\title{
Head impacts in youth national hockey leagues in Slovakia: a retrospective analysis of four seasons
}

\author{
Marek Majdan ${ }^{1, \star}$, Igor Toth ${ }^{2, \star}$, Patrik Barila ${ }^{2}$, Pavol Peracek ${ }^{2}$, Janka Perackova ${ }^{3}$, Silvio Parnican $^{2}$, \\ Martin Cente ${ }^{4}$ and Peter Filipcik ${ }^{4}$ \\ ${ }^{1}$ Department of Public Health, Institute for Global Health and Epidemiology, Faculty of Health Sciences and Social Work, \\ Trnava University, Trnava, Slovakia \\ ${ }^{2}$ Department of Sports Games, Faculty of Physical Education and Sport, Comenius University in Bratislava, Bratislava, \\ Slovakia \\ ${ }^{3}$ Department of Sport Science in Educology and Humanities, Faculty of Physical Education and Sport, Comenius University \\ in Bratislava, Bratislava, Slovakia \\ ${ }^{4}$ Institute of Neuroimmunology, Slovak Academy of Sciences, Bratislava, Slovakia
}

\begin{abstract}
Traumatic brain injury in contact sports can lead to serious health consequences either immediately or later in the life of injured subjects. The objective of this study was to estimate the incidence of head impacts in the Under 18 (U18) and Under 20 (U20) junior ice-hockey leagues in Slovakia over the seasons 2013/2014-2016/2017 using data from official game statistics. Incidence risks (IR) per 1000 athlete exposures were calculated for the season and stratified by a period of the game, by month, round, and part of the season. IR of head impacts ranged from 2.09 (95\%CI: 2.07-2.12) to 2.89 (95\%CI: $2.87-2.92$ ) in the U18 league and from 2.14 (95\% CI: $2.12-2.17$ ) to 4.06 (95\%CI: 4.02-4.09) in the U20. Higher IR was observed in the latter periods of games. This study brings first data on the incidence of concussions in youth ice-hockey leagues in Slovakia and calls for immediate implementation of measures to prevent these injuries.
\end{abstract}

Key words: Traumatic brain injury — Head impact — Neuropathology — Epidemiology

\section{Introduction}

Traumatic brain injuries (TBI) are a major public health and societal challenge on a global scale. Every year, an estimated 57,000 people die and 1.5 million are admitted to a hospital due to a TBI in the European Union (Majdan et al. 2016), with each TBI-related death associated with about 25 years of lost life (Majdan et al. 2017). Based on a cohort of over 4500 patients from 58 European centres enrolled in the

\footnotetext{
* These authors contributed equally to the manuscript.

Correspondence to: Marek Majdan, Department of Public Health, Institute for Global Health and Epidemiology, Faculty of Health Sciences and Social Work, Trnava University, 91843 Trnava, Slovakia

E-mail:mmajdan@truni.sk
}

CENTER-TBI study, most TBI cases are mild (68\%), with proportions of over $95 \%$ of mild TBI (mTBI) in those only admitted to Emergency department or to normal hospital wards (e.g. not treated at Intensive care unit) (Steyerberg et al. 2019). The major problem with head impact associated injuries is that they can cause illnesses, which are not recognized early enough, therefore are not reported and patient can live for a long period of time with chronic subclinical disease. Diagnostics of TBI and thereafter prediction of consequences in context of neurodegenerative and neuropsychiatric disorders are still under development. The estimation of TBI severity and degree of brain damage relies recently on several different tests. The method of choice is Glasgow Coma Scale, which although developed more than 40 years ago, still represents the most recommended non-invasive test (Teasdale et al. 2014; Jain and Iverson 2021). Neuroimaging

(c) The Authors 2021. This is an open access article under the terms of the Creative Commons Attribution-NonCommercial 4.0 International License (https://creativecommons.org/licenses/by-nc/4.0/), which permits non-commercial use, distribution, and reproduction in any medium, provided the original work is properly cited. 
is highly informative and efficient approaches for estimation of TBI consequences, however, at the level of microstructural and cellular changes, are not yet sensitive enough to make a definitive in vivo diagnosis; the strengths and limitations of neuroimaging were reviewed recently (Mayer and Quinn 2021). Development of biochemical markers, either proteins or nucleic acid, specifically those identified in peripheral tissues (Guedes et al. 2020; Sandmo et al. 2020), can not only serve as a diagnostics, but they can point to the molecular mechanisms associated with pathological processes induced by TBI and help to predict the treatment strategy.

Recent studies show that mTBI and specifically repeated mTBI can have long-term consequences and increase the risk of neurodegenerative diseases later in life (Ling et al. 2015; Pan et al. 2016). In addition, evidence suggests that even a single mild TBI may lead to the dementia (Graham and Sharp 2019). Thus, TBI should be considered a major risk factor for various forms of neuropathy, including severe chronic neurodegenerative disorders such as Parkinson's disease and Alzheimer's disease, which were linked to the history of TBI (Phillips and Woessner 2015; Kulbe and Geddes 2016; Washington et al. 2016; Mackay et al. 2019). The link from TBI to neurodegeneration is represented by the presence of molecular markers such as beta amyloid, tau protein, a-synuclein and TDP-43, which can be released from injured neurons. As published time ago and recently reviewed (Blennow et al. 2012; Delic et al. 2020) the formation of amyloid plaques, neurofibrillary tangles and TDP-43 neuropathologies goes hand in hand with the appearance of post-TBI syndromes. It is well known that these high molecular aggregates are difficult to dissolve, they are prone to propagate throughout the brain and exert the toxicity to different brain structures (Walker 2018). Disruption of blood brain barrier and persistent neuroinflammation are further events which are initiated by TBI and can significantly accelerate processes of subclinical neurodegeneration. Once the neuropathological symptoms become obvious it is too late to start with the treatment. Moreover the neurodegenerative and neuropsychiatric disorders are not yet pharmacologically treatable. Although some forms of the symptomatic treatment are available (Duraes et al. 2018; Cummings 2021), no efficient disease-modifying therapy exists. Such a situation persists in spite of the fact that there are currently about 121 agents focused to treatment of neuropsychiatric diseases in different phases of clinical trials, and $80 \%$ of them are focused on disease modification (Gijbels et al. 1994). Still holds true, that prevention is the only and readily available tool in the fight against TBI-induced neurodegeneration.

Specifically, it has been well documented that sportassociated TBI can lead to chronic traumatic encephalopathy (CTE), which was recognised officially as a new clinical unit in American football players and professional wrestlers
(Omalu et al. 2005). Ten years later, The National Institute of Neurological Disorders and Stroke determined the neuropathological definition of CTE (McKee et al. 2016). CTE was later diagnosed post-mortem in players of American football, basketball, rugby, in professional soldiers, as well as in brains of ice hockey players (McKee et al. 2014). At the molecular level CTE is defined as tauopathy and is characterized by intracellular tau protein inclusions similar as observed in Alzheimer's disease. However. the occurrence of head impact in different part of the head can most probably lead to various forms of neuropathy which can include different forms of dementia.

Sports-related injuries are a frequent cause of TBI in general (Maas et al. 2017). A review of 11 population-based studies revealed that $1.2-30 \%$ of all TBI are sport-related (Theadom et al. 2020). The highest incidence rates of concussions were in rugby, ice-hockey and American football - the pooled rate for ice-hockey was estimated at 1.2 per 1000 athlete exposures (AE) (Pfister et al. 2016). Another systematic review estimated that in European hockey leagues, between $2-7 \%$ of all sustained injuries lead to a concussion (Ruhe et al. 2014). In general, however, research into incidence of TBI in ice-hockey in Europe is lagging behind whereas most existing data comes from North American studies (Ruhe et al. 2014; Pfister et al. 2016; Theadom et al. 2020).

This lack of information is alarming, especially in countries of Central Eastern Europe, where ice hockey has been traditionally a widely popular sport, such as Slovakia or the Czech Republic. Slovakia, a nation of about 5.5 million has 10,910 officially registered ice hockey players with 8819 ( $81 \%)$ of them being under 20 years and 631 being females. There are 110 ice hockey clubs, 71 indoor and 28 outdoor rinks (Slovakia 2020). These numbers do not reflect players in amateur leagues, and thus the number of active players is presumably even higher. Yet, there is no existing study that produced estimates of TBI incidence in any of the Slovak hockey leagues that could be compared to data published for other leagues or used as input information for prevention strategies.

One of the key issues in comparing TBI incidence in ice hockey across studies is the difference in case definitions and in the used indicators (Ruhe et al. 2014; Pfister et al. 2016; Maas et al. 2017). Optimally, all cases reported as concussions or TBI are confirmed by a medical exam. While this approach ensures medical confirmation of an injury to the brain, it may also cause selection bias due to non-unified procedures applied or due to potential exclusion of falsely negative cases. Our approach in this study relies on game statistics, where head impacts are being recorded as defined by the Ice hockey rules of game published by the International Ice Hockey Federation (IIHF 2018). This ensures, that all head impacts potentially involving a TBI are recorded using a unified definition. 
The aim of this study was to estimate the incidence of head impacts and their patterns in the Under 18 (U18) and Under 20 (U20) youth ice-hockey leagues in Slovakia over four seasons using data from official game statistics. Our data can be used as arguments for implementation of measures to strengthen the prevention of head injuries in youth icehockey players and to intensify a call for further research into the early diagnostics and treatment of traumatic brain injuries after the sport-related head impacts.

\section{Methods}

The presented study is a cross-sectional analysis of head impacts in the U18 and U20 ice hockey leagues in Slovakia. The U18 league includes players ages 16 to 18 years old, while the U20 includes players 19 or 20 years old. A total of four seasons were followed up in their entirety (e.g. all games were included): 2013/2014, 2014/2015, 2015/2016 and 2016/2017. Both, the U18 and the U20 leagues are leagues officially managed by the SIHF. The basic characteristics of the hockey leagues were analyzed are presented in Table 1.

The data used in this study were retrospectively extracted from official game reports which are archived by the SIHF. These reports include all game statistics including the number of fouls and specifically the number of head impacts. The number of such impacts and their time of occurrence (e.g. the date of the game, the period of the game and the minute of game) were extracted by three of the authors (IT, $\mathrm{PB}$ and SP) in parallel, and after extraction the numbers were crosschecked in order to prevent errors. These data were then entered into a database and further analysed.

An event was defined as head impact occurring during the game and judged as such by the main referee, in accordance with the Ice hockey rules of play. These impacts are presented as counts and as incidence risks per $1000 \mathrm{AE}$. The incidence risks (IR) were calculated as

$I R=\frac{\sum \text { Attacks }}{\sum A E} \times 1000$

Table 1. Characteristics of the analyzed youth hockey leagues

\begin{tabular}{rccccc}
\hline \multirow{2}{*}{ Season } & \multicolumn{2}{c}{ U18 league } & & \multicolumn{2}{c}{ U20 league } \\
\cline { 2 - 3 } \cline { 5 - 6 } & Teams & Players & & Teams & Players \\
\hline $2013 / 2014$ & 15 & 375 & & 12 & 300 \\
$2014 / 2015$ & 15 & 375 & & 12 & 300 \\
$2015 / 2016$ & 16 & 400 & & 18 & 450 \\
$2016 / 2017$ & 16 & 400 & & 13 & 325 \\
\hline
\end{tabular}

$\mathrm{U} 18$, hockey players from 16 to 18 years old; U20, hockey players 19 or 20 years old. and are presented along with a 95\% confidence interval (CI). To calculate AE, a unified value of 20 players involved was used for all games.

In order to compare the rates by various aspects, incidence risk ratios (IRR) were calculated along with 95\%CI. These ratios quantify the difference between IR, e.g. an IRR of 2 means that the respective group has twice the risk compared to the reference.

All results are presented separately for the U18 and U20 leagues. First, we present summary counts and IR for each season. Seasons were then divided into the basic part and play-offs and separate counts and IR are presented for each part. Secondly, various aspects were used to divide the games and season and the respective IR were compared using IRR. In such manner, IR were compared between the thirds of the game (separate for each season), the months during the season and by round of game (all seasons combined). The $\mathrm{R}$ statistical language was used for all analyses (Team R Core 2017).

\section{Results}

\section{Comparison of the U18 and U20 league}

The number of reported head impacts ranged from 34 in seasons 2013/2014 and 2014/2015 to the highest observed 48 head impacts in season $2015 / 16$. On average, there were 38.5 head impacts per season, with most of them occurring during the basic part (ranging from $82 \%$ in the 2013/2014 season to $89 \%$ in the $2016-2017$ season; $86 \%$ on average for the four seasons). Table 2 presents the summary of the

Table 2. Incidence risk of suspected TBI per 1000 athlete exposures in youth hockey players in the Under 18 national hockey league in Slovakia by season and season part

\begin{tabular}{llcccc}
\hline Season & Season part & $\begin{array}{c}\text { Head } \\
\text { impacts }\end{array}$ & Games & IR & 95\%CI \\
\hline \multirow{2}{*}{$2013 / 2014$} & Overall & 34 & 406 & 2.09 & $2.07-2.12$ \\
& Basic & 28 & 352 & 1.99 & $1.97-2.01$ \\
& Play offs & 6 & 54 & 2.78 & $2.71-2.85$ \\
\hline \multirow{2}{*}{$2014 / 2015$} & Overall & 34 & 416 & 2.04 & $2.02-2.07$ \\
& Basic & 29 & 352 & 2.06 & $2.04-2.08$ \\
& Play offs & 5 & 64 & 1.96 & $1.91-2.01$ \\
\hline \multirow{2}{*}{$2015 / 2016$} & Overall & 48 & 415 & 2.89 & $2.87-2.92$ \\
& Basic & 41 & 352 & 2.91 & $2.88-2.94$ \\
& Play offs & 7 & 63 & 2.78 & $2.71-2.84$ \\
\hline \multirow{2}{*}{$2016 / 2017$ Overall } & 38 & 416 & 2.28 & $2.26-2.31$ \\
& Basic & 34 & 348 & 2.44 & $2.42-2.47$ \\
& Play offs & 4 & 68 & 1.47 & $1.43-1.52$ \\
\hline
\end{tabular}

IR, incidence risk; CI, confidence interval. 

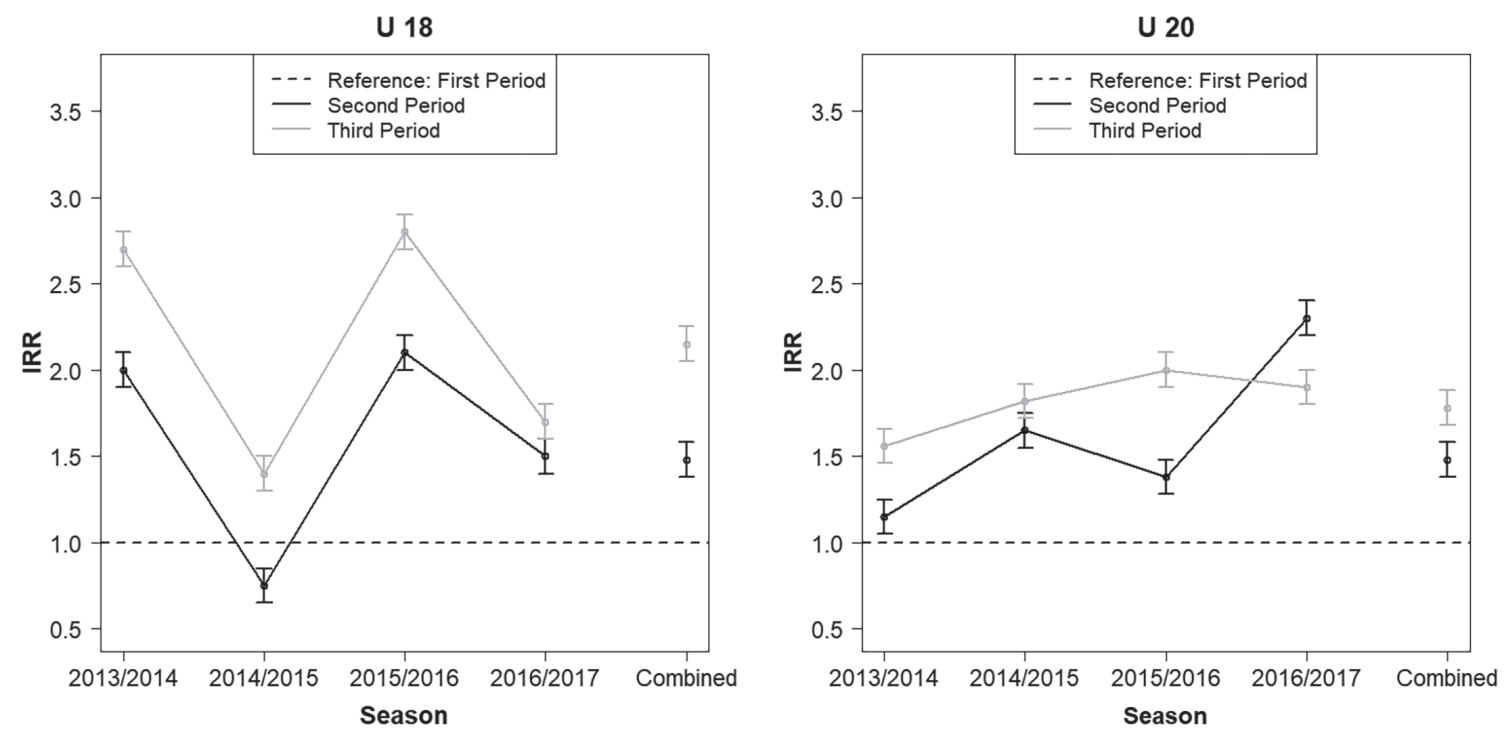

Figure 1. Incidence risk ratios (IRR) with $95 \% \mathrm{CI}$ of head impacts between periods of game for each analyzed season and all seasons combined in the Under 18 (U18) and Under 20 (U20) national hockey leagues in Slovakia. IRR are calculated using the incidence risk (IR) for the first period of the games in each season as reference, to which IR for the second and third periods are compared. CI, confidence interval. Periods of game refer to the three 20 minute parts of a hockey game.

number of head impacts as counts and recalculated to IR for the four seasons presented separately for each part of the season for the U18 league.

These translated into overall IR (e.g, including games during the basic part and during the play-offs) ranging from 2.04 head impacts per $1000 \mathrm{AE}$ in the 2014/2015 season to 2.89 head impacts per 1000 AE in the 2015/2016 season. While the IR for the play-off games was higher in the 2013-2014 season, than during the basic part $(2.78$

Table 3. Incidence risk of suspected TBI per 1000 athlete exposures in youth hockey players in the Under 20 national hockey league in Slovakia by season and season part

\begin{tabular}{llcccc}
\hline Season & Season part & $\begin{array}{c}\text { Head } \\
\text { impacts }\end{array}$ & Games & IR & $95 \%$ CI \\
\hline \multirow{2}{*}{$2013 / 2014$} & Overall & 26 & 303 & 2.14 & $2.12-2.17$ \\
& Basic & 21 & 264 & 1.99 & $1.96-2.02$ \\
& Play offs & 5 & 39 & 3.21 & $3.12-3.29$ \\
\hline \multirow{2}{*}{$2014 / 2015$} & Overall & 50 & 308 & 4.06 & $4.02-4.09$ \\
& Basic & 44 & 264 & 4.16 & $4.12-4.21$ \\
& Play offs & 6 & 44 & 3.41 & $3.32-3.49$ \\
\hline \multirow{2}{*}{$2015 / 2016$} & Overall & 40 & 458 & 2.18 & $2.16-2.21$ \\
& Basic & 31 & 306 & 2.53 & $2.51-2.56$ \\
& Play offs & 9 & 152 & 1.48 & $1.45-1.51$ \\
\hline \multirow{2}{*}{$2016 / 2017$} & Overall & 51 & 345 & 3.7 & $3.66-3.73$ \\
& Basic & 46 & 313 & 3.67 & $3.64-3.71$ \\
& Play offs & 5 & 32 & 3.91 & $3.8-4.02$ \\
\hline
\end{tabular}

IR, incidence risk; CI, confidence interval. vs. 1.99 head impacts per $1000 \mathrm{AE}$ ), in seasons 2014/2015 to $2016 / 2017$, the IR were higher in the basic part. Thus, no clear patterns of variation between the basic part and play-offs were observed, that would apply for all analyzed seasons.

Overall, the number of observed head impacts for the U20 hockey league for the whole season ranged from 26 in the $2013 / 2014$ season to 51 in the $2016 / 2017$ season. Similarly to the U18 league, most of the head impacts were observed during the basic part games - ranging from $78 \%$ in the $2015 / 2016$ season to $90 \%$ in the $2016 / 2017$ season; on average $85 \%$ of head impacts occurred during the basic part of the season. Table 3 presents the summary of the number of head impacts as counts and recalculated to IR for the four seasons presented separately for each part of the season for the U20 league.

The corresponding IR ranged from 2.14 in the 2013/2014 season to 4.06 head impacts per $1000 \mathrm{AE}$ in the 2014/2015 season (95\%CI: 4.02-4.09). As in the U18 league, the rates were interchangeably higher in the basic part or play-offs with no apparent trend observed: in the 2013/2014 and the 2016/2017 seasons, higher IR were observed during play-offs (1.99vs. 3.21 head impacts per $100 \mathrm{AE}$, and 3.67 vs. 3.91 head impacts per $1000 \mathrm{AE}$, respectively), while a reversed trend was observed for 2014/2015 and 2015/2016.

In general, in the U20 league compared to the U18 league, the rates were higher for overall as well as for each part of the season in all seasons, except 2015/2016 where this was reversed. This indicates, that the risk of head impacts can in general be considered higher in the U20 league. 


\section{Risk of head impacts by period of the game}

Differences in rates of head impacts were observed between the periods of the game (presented as IRR of head impacts by period of the game in Figure 1). The first period is taken for baseline and all presented ratios are related to the rate for this period. In both leagues, there is a clear pattern which shows an increasing risk of head impacts in the later periods (with an exception of season 2014/15 in the U18 league where the IR was lowest in the second period). IRR are presented for all seasons separately and overall for all analyzed games together. The summary estimates suggest that the risk of head impacts in the U18 league was higher in the second period by a factor of 1.5 (95\%CI: 1.47-1.52), and in the comparison of third versus first period the IRR was 2.02 (95\%CI: 1.99-2.06). Similarly, in the U20 league, the risk was significantly higher in later periods compared to the first. The overall IRR were 1.48 (95\%CI: 1.45-1.51) for the second $v$ s. first period comparison and 1.81 (95\%CI: $1.78-1.85)$ for third $v s$. first period.

\section{Incidence risk by month of season}

Differences in risk of head impacts were also observed between months of the season; in Figure 2, IR are plotted for each month of the season for both leagues in order to present the trends in this respect. Clearly, the least risky were the end of season games (e.g. the play-offs) where no head impacts were recorded in any of the analyzed seasons. Overall, the IR appear to be similar for games between January and April, whereas larger variation is present between September and December, with mostly higher rates in the U20 league.

\section{Discussion}

We conducted a cross-sectional analysis of the incidence of head impacts in the U18 and U20 youth ice hockey leagues in Slovakia during four seasons. We found that in the U18, the IR of head impacts ranged from 2.04 to 2.89 and in the U20 from 2.14 to 4.06 per $1000 \mathrm{AE}$ for the analysed seasons. Significantly higher IR were observed in later periods of games: overall, the risk of head impact was higher by a factor of 1.5 in the second and by 2.02 in the third period compared to the IR for the first period in the U18. In the U20 these factors were 1.48 and 1.81 .

Although, a number of previous studies estimated the incidence of concussions or head injuries and concussions in youth hockey leagues, it is difficult to directly compare these findings with our results as there are methodological differences between studies. However, a cautious general level of comparison is possible.

A recent systematic review used estimates from four studies (all from North America) to generate a pooled incidence of 1.2 concussions per $1000 \mathrm{AE}$ (Pfister et al. 2016). A study following 397 youth ice hockey players in the US estimated an IR of 1.58 concussions per $1000 \mathrm{AE}$ (Kontos et al. 2016). These estimates are lower than our findings, which could partly be caused by the fact that all concussions were confirmed medically or using a standardized tool resulting to stricter inclusion criteria. Another systematic review reports IR ranging between 0.72 and 1.81 per $1000 \mathrm{AE}$ based on 17 studies (Ruhe et al. 2014), and observes that the proportions of concussions from the overall number of injuries in youth ice hockey from North American studies is substantially lower that in studies from Europe $(2-7 \% v s$. 5.3-18.6\%) - which may be yet another cause of higher IR in our study. An extensive review of concussions in contact sports reports season incidences for men's ice hockey ranging from 0.41 to 1.55 per $1000 \mathrm{AE}$ (matches and practice combined), with higher estimates for match-only based analyses (1.49 to 7.50 per $1000 \mathrm{AE}$ ) (Prien et al. 2018).

Thus, in general, considering the above-mentioned explanations of generally higher IR in our study compared to the published literature, our results seem to fall within the

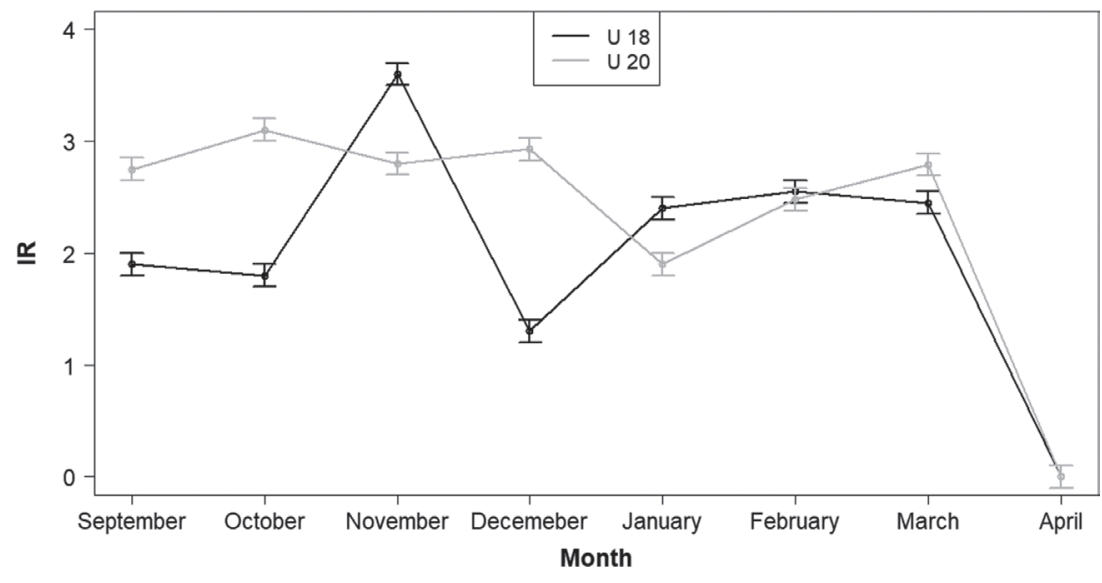

Figure 2. Incidence risk (IR) with 95\%CI of head impacts by months of the season in youth hockey players in the Under 18 (U18) and Under 20 (U20) national hockey leagues in Slovakia in seasons 2013/2014-2016/2017. $\mathrm{CI}$, confidence interval; $\mathrm{AE}$, athlete exposure. 
range of incidences expected based on the available knowledge on the topic.

Several factors could influence the observed differences in head impacts rates between seasons, including varying long-term fatigue (especially among key players), varying composition of teams (e.g, players changing teams) which influences the overall pattern of play of the team (e.g, more "physical“), longer-term game strategies, or individual situational differences during fouls or physical contacts (e.g, body posture at the time of head impacts). On the other hand, the observed differences within the game (between the thirds) may be attributed to factors, such as increasing fatigue of players during the game, or the importance of the game, which has an impact on the overall effort and risktaking behaviour. The data available for this study did not allow to evaluate these associations in detail. However, the magnitude of the observed differences warrants for further studies that could elucidate on these relationships.

By analysing the incidence of head impacts, we attempted to indirectly estimate the incidence of concussions in two youth hockey leagues in Slovakia. As suggested by the similarity of our results to the findings of previous studies with more rigid case definition (e.g. medically confirmed concussion), this method may be robust enough to be used as a surrogate method to estimate the incidence of concussions. As it is based on routinely collected data, they may be used to routinely monitor the trends and circumstances of the resulting injuries in official hockey leagues in Slovakia or elsewhere. We do not provide evidence about the sensitivity of head impacts to estimate concussions, but such studies may be suggested for further research based on our findings.

To our knowledge, this is the first study using a scientific approach to estimate the incidence of head impacts in ice hockey in Slovakia. Given the popularity and involvement in the sport in Slovakia (Slovakia, Hockey 2020; https://www. hockeyslovakia.sk/en.), it can serve to call for implementation of measures to tackle these types of injuries. Although several tools and programs exist to prevent head injuries in ice hockey (Emery et al. 2017), or assess them on side-line (Smith et al. 2017), their implementation in Slovak ice hockey leagues is lagging behind.

There are limitations to our study pertaining mainly to the character of the data used in the analyses. First, there is no evidence evaluating the sensitivity of using head impacts to estimate TBI - our findings may therefore overestimate the number of concussions when used for such purposes. Second, additional selection bias may have occurred by the fact that the head impacts are recorded in the game statistics only if they are judged like that by the referee - individual variation of the judging practice between the referees could cause some over- or under-estimation of the true number of impacts.
Our study suggests that the incidence of concussions in youth ice-hockey leagues in Slovakia may be on levels similar to those reported in other leagues. Immediate implementation of measures to prevent these injuries is needed. The latter is the period of the game, the higher is the risk of head impact - this should be considered when planning prevention.

Conflicts of interest. All authors declare no conflicts of interests.

Acknowledgements. The work was supported by grants from the Slovak Research and Development Agency "APVV-170668", APVV-19-0568 and "APVV-20-0615". Work was further supported by JPsustaiND, Grant agreement ID: 681043. Dr. Perackova and Dr. Filipcik were further supported by the grant "VEGA 2/0154/19" from the Ministry of Education, Science, Research and Sport of the Slovak Republic and Slovak Academy of Sciences. Part of the work of Dr. Majdan was supported by the CENTER-TBI project, grant \# 602150 from the European Commission.

Authors' contributions. MM, IT and PF designed the study and drafted the manuscript. All authors substantially contributed to the conception and design of the work, the acquisition, analysis and interpretation of data, revised it critically for important intellectual content, approved the final version of the manuscript and agreed to be accountable for all aspects of the work in ensuring that questions related to the accuracy or integrity of any part of the work are appropriately investigated and resolved.

Ethics approval. This study is based on publicly available secondary data and no ethics approval was required.

\section{References}

Blennow K, Hardy J, Zetterberg H (2012): The neuropathology and neurobiology of traumatic brain injury. Neuron 76, 886-899 https://doi.org/10.1016/j.neuron.2012.11.021

Cummings J (2021): New approaches to symptomatic treatments for Alzheimer's disease. Mol. Neurodegener. 16, 2 https://doi.org/10.1186/s13024-021-00424-9

Delic V, Beck KD, Pang KCH, Citron BA (2020): Biological links between traumatic brain injury and Parkinson's disease. Acta Neuropathol. Commun. 8, 45 https://doi.org/10.1186/s40478-020-00924-7

Duraes F, Pinto M, Sousa E (2018): Old drugs as new treatments for neurodegenerative diseases. Pharmaceuticals (Basel) 11, 44 https://doi.org/10.3390/ph11020044

Emery CA, Black AM, Kolstad A, Martinez G, Nettel-Aguirre A, Engebretsen L, Johnston K, Kissick J, Maddocks D, Tator C, et al. (2017): What strategies can be used to effectively reduce the risk of concussion in sport? A systematic review. Br. J. Sports Med. 51, 978-984

https://doi.org/10.1136/bjsports-2016-097452 
International Ice Hockey Federation (2018): IIHF Official Rule Book 2018-2022. Bratislava, SZLH

Gijbels K, Galardy RE, Steinman L (1994): Reversal of experimental autoimmune encephalomyelitis with a hydroxamate inhibitor of matrix metalloproteases. J. Clin. Invest. 94, 2177-2182 https://doi.org/10.1172/JCI117578

Graham NS, Sharp DJ (2019): Understanding neurodegeneration after traumatic brain injury: from mechanisms to clinical trials in dementia. J. Neurol. Neurosurg. Psychiatry 90, 1221-1233 https://doi.org/10.1136/jnnp-2017-317557

Guedes VA, Devoto C, Leete J, Sass D, Acott JD, Mithani S, Gill JM (2020): Extracellular vesicle proteins and microRNAs as biomarkers for traumatic brain injury. Front. Neurol. 11, 663 https://doi.org/10.3389/fneur.2020.00663

Jain S, Iverson LM (2021): Glasgow Coma Scale. StatPearls Publishing

Kontos AP, Elbin RJ, Sufrinko A, Dakan S, Bookwalter K, Price A, Meehan WP, 3rd, Collins MW (2016): Incidence of concussion in youth ice hockey players. Pediatrics 137, e20151633 https://doi.org/10.1542/peds.2015-1633

Kulbe JR, Geddes JW (2016): Current status of fluid biomarkers in mild traumatic brain injury. Exp. Neurol. 275, 334-352 https://doi.org/10.1016/j.expneurol.2015.05.004

Ling H, Hardy J, Zetterberg H (2015): Neurological consequences of traumatic brain injuries in sports. Mol. Cell. Neurosci. 66, 114-122 https://doi.org/10.1016/j.mcn.2015.03.012

Maas AIR, Menon DK, Adelson PD, Andelic N, Bell MJ, Belli A, Bragge P, Brazinova A, Buki A, Chesnut RM, et al. (2017): Traumatic brain injury: integrated approaches to improve prevention, clinical care, and research. Lancet Neurol. 16, 987-1048 https://doi.org/10.1016/S1474-4422(17)30371-X

Mackay DF, Russell ER, Stewart K, MacLean JA, Pell JP, Stewart W (2019): Neurodegenerative disease mortality among former professional soccer players. N. Engl. J. Med. 381, 1801-1808 https://doi.org/10.1056/NEJMoa1908483

Majdan M, Plancikova D, Brazinova A, Rusnak M, Nieboer D, Feigin V, Maas A (2016): Epidemiology of traumatic brain injuries in Europe: a cross-sectional analysis. Lancet Public Health 1, e76-e83 https://doi.org/10.1016/S2468-2667(16)30017-2

Majdan M, Plancikova D, Maas A, Polinder S, Feigin V, Theadom A, Rusnak M, Brazinova A, Haagsma J (2017): Years of life lost due to traumatic brain injury in Europe: A cross-sectional analysis of 16 countries. PLoS Med. 14, e1002331 https://doi.org/10.1371/journal.pmed.1002331

Mayer AR, Quinn DK (2021): Neuroimaging biomarkers of newonset psychiatric disorders following traumatic brain injury. Biol. Psychiatry (in press) https://doi.org/10.1016/j.biopsych.2021.06.005

McKee AC, Cairns NJ, Dickson DW, Folkerth RD, Keene CD, Litvan I, Perl DP, Stein TD, Vonsattel JP, Stewart Y (2016): The first NINDS/NIBIB consensus meeting to define neuropathological criteria for the diagnosis of chronic traumatic encephalopathy. Acta Neuropathol. 131, 75-86 https://doi.org/10.1007/s00401-015-1515-Z
McKee AC, Daneshvar DH, Alvarez VE, Stein TD (2014): The neuropathology of sport. Acta Neuropathol. 127, 29-51 https://doi.org/10.1007/s00401-013-1230-6

Omalu BI, DeKosky ST, Minster RL, Kamboh MI, Hamilton RL, Wecht CH (2005): Chronic traumatic encephalopathy in a National Football League player. Neurosurgery 57, 128-134 https://doi.org/10.1227/01.NEU.0000163407.92769.ED

Pan J, Connolly ID, Dangelmajer S, Kintzing J, Ho AL, Grant G (2016): Sports-related brain injuries: connecting pathology to diagnosis. Neurosurg. Focus 40, E14 https://doi.org/10.3171/2016.1.FOCUS15607

Pfister T, Pfister K, Hagel B, Ghali WA, Ronksley PE (2016): The incidence of concussion in youth sports: a systematic review and meta-analysis. Br. J. Sports Med. 50, 292-297 https://doi.org/10.1136/bjsports-2015-094978

Phillips S, Woessner D (2015): Sports-related traumatic brain injury. Prim. Care 42, 243-248 https://doi.org/10.1016/j.pop.2015.01.010

Prien A, Grafe A, Rossler R, Junge A, Verhagen E (2018): Epidemiology of head injuries focusing on concussions in team contact sports: A systematic review. Sports Med. 48, 953-969 https://doi.org/10.1007/s40279-017-0854-4

Ruhe A, Gansslen A, Klein W (2014): The incidence of concussion in professional and collegiate ice hockey: are we making progress? A systematic review of the literature. Br. J. Sports Med. 48, 102-106 https://doi.org/10.1136/bjsports-2012-091609

Sandmo SB, Filipcik P, Cente M, Hanes J, Andersen TE, StraumeNaesheim TM, Bahr R (2020): Neurofilament light and tau in serum after head-impact exposure in soccer. Brain Inj. 34, 602-609 https://doi.org/10.1080/02699052.2020.1725129

Slovakia, Hockey (2020): Slovak Hockey in Numbers. Hockey Slovakia

Smith AM, Stuart MJ, Roberts WO, Dodick DW, Finnoff JT, Jorgensen JK, Krause DA (2017): Concussion in ice hockey: Current gaps and future directions in an objective diagnosis. Clin. J. Sport Med. 27, 503-509 https://doi.org/10.1097/JSM.0000000000000412

Steyerberg EW, Wiegers E, C. Sewalt, A. Buki, G. Citerio, V. De Keyser, A. Ercole, K. Kunzmann, L. Lanyon, F. Lecky, et al. (2019): Case-mix, care pathways, and outcomes in patients with traumatic brain injury in CENTER-TBI: a European prospective, multicentre, longitudinal, cohort study. Lancet Neurol. 18, 923-934 https://doi.org/10.1016/S1474-4422(19)30232-7

Team R Core (2017): R: A language and environment for statistical computing. In: R Foundation for Statistical Computing. Vienna, Austria

Teasdale G, Maas A, Lecky F, Manley G, Stocchetti N, Murray G (2014): The Glasgow coma scale at 40 years: standing the test of time. Lancet Neurol. 13, 844-854 https://doi.org/10.1016/S1474-4422(14)70120-6

Theadom A, Mahon S, Hume P, Starkey N, Barker-Collo S, Jones K, Majdan M, Feigin VL (2020): Incidence of sports-related traumatic brain injury of all severities: A systematic review. Neuroepidemiology 54, 192-199 https://doi.org/10.1159/000505424 
Walker LC (2018): Prion-like mechanisms in Alzheimer disease. Handb. Clin. Neurol. 153, 303-319 https://doi.org/10.1016/B978-0-444-63945-5.00016-7

Washington PM, Villapol S, Burns MP (2016): Polypathology and dementia after brain trauma: Does brain injury trigger distinct neurodegenerative diseases, or should they be clas- sified together as traumatic encephalopathy? Exp. Neurol. 275, 381-388

https://doi.org/10.1016/j.expneurol.2015.06.015

Received: June 18, 2021

Final version accepted: October 8, 2021 